Artigos Originais

\title{
A MULHER E O DESLOCAMENTO TURÍSTICO NO MUNDO CONTEMPORÂNEO: UMA CONTRIBUIÇÃO TEÓRICO- METODOLÓGICA AOS ESTUDOS DO TURISMO
}

Women and tourist displacement in the contemporary world: a theoretical-methodological contribution to tourism studies

La mujer y el desplazamiento turístico en el mundo contemporáneo: una contribución teórico-metodológica a los estudios turísticos

Giulia Praça Firmino Sales de Melo

Universidade Estácio de Sá (UNESA), Brasil

giuliafirmino@gmail.com

DOI: https://doi.org/10.18472/cvt.20n2.2020.1764

Redalyc: http://www.redalyc.org/articulo.oa?

$\mathrm{id}=115464354003$

Ítalo César de Moura Soeiro

Universidade Federal de Pernambuco (UFPE), Brasil

italosoeiro@gmail.com

Recepción: 01 Octubre 2019

Aprobación: 16 Junio 2020

\section{Resumo:}

Tomando as viagens de mulheres na modalidade solo como objeto empírico, o presente artigo objetiva discutir a incompatibilidade da representação patriarcal da mulher com seu deslocamento livre. Para tanto, além de realizar uma revisão blibliográfica, partiu-se da análise de blogs de viagens, mais especificamente, de postagens de "dicas para mulheres que viajam sozinhas". Isso, pois entendese que a busca por dica (breve conselho/informação privilegiada) demonstra uma comunicação estratégica entre as mulheres para tentar reduzir as violências presentes no processo de deslocamento. Assim, as dicas expressam a condensação de experiências individuais/coletivas e serve-nos como estruturas de redução fenomenológica intersubjetiva; serve-nos como material analítico capaz de aclarar um pouco mais essa relação conflituosa entre a representação patriarcal da mulher e o seu deslocamento. Ao final, conclui-se que o deslocamento da mulher é dificultado em múltiplas escalas, incluindo a dos deslocamentos turísticos; que o caráter simbólico e ideológico que marca sua representação numa sociedade patriarcal é onde reside a maior parcela dos obstáculos à liberdade.

PalaVras-Chave: Patriarcado, Viajante solo, Mulheres, Liberdade, Turismo.

\section{Abstract:}

Considering solo women travels as an empirical object, in this article we discuss the incompatibility of the patriarchal representation of women with their free movement. therefore, besides to perform a blibliographical review, we started with the analysis of travel blogs, more specifically, of posts of "tips for women who travel alone". This is because it is understood that the search for a tip (brief advice / privileged information) demonstrates strategic communication between women to try to reduce the violence presented in the displacement process. Thus, the tips express the condensation of individual and/or collective experiences and served as structures of intersubjective phenomenological reduction; it serves as analytical material capable of clarifying a little more this conflicting relationship between the patriarchal representation of women and their displacement. In the end, it is concluded that the displacement of women is hampered on multiple scales, including that of tourist displacements; that the symbolic and ideological character that marks its representation in a patriarchal society is where most of the obstacles to freedom reside.

KEYWORDS: Patriarchate, Solo traveler, Women, Freedom, Tourism.

\section{Resumen:}

Tomando los viajes de las mujeres en modo individual como un objeto empírico, este artículo objetiva discutir la incompatibilidad de la representación patriarcal de las mujeres con su libre desplazamiento. Con este fin, además de realizar una revisión blibliográfica, se analisaron publicaciones de "pistas para mujeres que viajan solas" en blogs de viajes. Esto se debe a que se entiende que la búsqueda de una pista (consejo breve / información privilegiada) demuestra la comunicación estratégica entre las mujeres 
para tratar de reducir la violencia presente en el proceso de desplazamiento. Así, las pistas expresan la condensación de experiencias individuales/colectivas y nos sirven como estructuras de reducción fenomenológica intersubjetiva; como material analítico capaz de aclarar la relación conflictiva entre la representación patriarcal de las mujeres y su desplazamiento. Al final, se concluye que el desplazamiento de las mujeres se ve obstaculizado en múltiples escalas, incluida la de los desplazamientos turísticos; que el carácter simbólico e ideológico que marca su representación en una sociedad patriarcal es donde residen la mayoría de los obstáculos a la libertad.

Palabras Clave: Patriarcado, Viajero solo, Mujer, Libertad, Turismo.

\section{INTRODUÇÃo}

Este artigo vem refletir sobre a mulher enquanto ser-potência e sua representação turvada pela ideologia de gênero produzida pelo conjunto de ideias e valores promovidos para manutenção do patriarcado. Neste artigo, busca-se compreender como a representação da mulher tem sido arquitetada, conjuntamente à outras representações, de forma incompatível aos deslocamentos livres. Mais especificamente, buscaremos entender tal processo através do deslocamento turístico de mulheres que viajam sozinhas, desacompanhadas. Assim, espera-se animar, dentro dos estudos do Turismo, discussões que ultrapassem a tradicional abordagem da economia-política; discussóes que iluminem o gênero como categoria interessante ao entendimento do Turismo[1].

Como a expressão “ideologia de gênero", recentemente, ganhou ampla divulgação junto ao senso comum, sendo esvaziada de seu sentido teórico, julga-se adequado aclarar em qual sentido tal termo é utilizado neste artigo, a saber: a identidade sexual do ser humano e suas condições de existência no mundo dependem, sobretudo, de seu entorno sócio-cultural, do meio ideológico, e não de uma variável meramente biológica como o sexo. A ideologia de gênero, portanto, é tratada aqui enquanto ideologia política que tem como objetivo a conquista e manutenção do poder entre os gêneros (Bourdier, 1996). Trata-se, assim, de reconhecer que as relações de poder entre gêneros, igualmente aos significados, valores e símbolos, divergem através das culturas, no tempo e no espaço.

Considerando que o Brasil foi colonizado por ocidentais, pode-se inferir que os homens brasileiros carregavam conceitos e valores, em relação à mulher, bem similares aos dos colonizadores. Portanto, a mulher no Brasil, historicamente, é vista sob o prisma da ideologia patriarcal. Ou seja, há, historicamente, em relação à mulher, uma exigência e imposição de docilidade, recato e submissão. Segundo Follador (2009), essas exigências e imposições ideológicas elaboraram um estereótipo patriarcal que relegava à mulher o espaço da casa e negava o deslocamento livre. Nesse sentido, cabe reconhecer que historicamente

[...] as mulheres no Brasil não tiveram muito espaço para expressar seus pensamentos e para gozar de algum lazer [...] $\mathrm{O}$ controle exercido pelos homens sobre elas atingia todos os campos de suas vidas, como o controle dentro de casa desde a infância, o controle ideológico mantido pelos ideais de recato, respeito, humildade e pela falta de instrução; por fim, a escolha de um marido que certamente manteria o mesmo controle sobre ela. (Follador, 2009, p.9)

Portanto, para entender os movimentos de turvar e de manipulação da representação da mulher a favor da manutenção do sistema social patriarcal, chega-se, inevitavelmente, ao conceito de ideologia. Ideologia é tomada aqui como uma posição a serviço de algum interesse, pessoal ou social e, por isto, é eminentemente justificadora; são todas as formas reducionistas de explicar o real. Contém, assim, um tom moralizante, persuasivo, distorce os fatos em seu favor e sugere um dever ser (Demo, 1981; Chauí, 1991). Sabendo disso e da capacidade de modificar a percepção da realidade em favor de um grupo, classe ou gênero através da ideologia, é possível sensibilizar-se para a existência de duas possíveis dimensões da realidade, a saber: a realidade enquanto potência, logo, o ser de fato, o noúmeno e da realidade criada em função de algo, portanto, capturada pelos sentidos turvados pela ideologia, o fenômeno, a representação.

Ainda nessa direção, traz-se Aristóteles (2012) para a construção de nossa argumentação. Segundo o qual, todo ser existente tem uma potência, ou seja, uma possibilidade de ser outra coisa - melhor ou 
pior, não se sabe. Porém, a potência nem sempre alcança o existir. Cabe aclarar que, na mulher, essa potência/possibilidade não alcança o existir livremente, pois está cerceada pelos valores estéticos e éticos da ideologia de gênero fruto do patriarcado. Para que essa potência/possibilidade possa se transformar em realidade, precisa-se da criação das condições propícias. Condições essas negadas às mulheres pela ideologia do patriarcado. Nesse sentido, entende-se mulher, aqui, como um ser-potência que, pela repressão sofrida pelas representações e conjuntos de ideias e instituições que sustentam o sistema patriarcal, tem sua liberdade no existir dificultada.

Assim sendo, mulher é um ser-potência que se dá como latência, como um conjunto de possibilidades realizadas e não realizadas; como o real e o possível, o visível e o invisível, o imediato e o mediato, a presença e a ausência. Se a mulher teria uma essência, essa seria, para nós, o "Real Possível", as possibilidades reais, o ser-potência.

Diante dessas noções abrem-se alguns questionamentos, a saber: o que nos impede de acessar a mulher-serpotência e ideologiza a representação da mulher? Quais os meios que possibilitam esse processo e a imposição da ideologia patriarcal? Em que medida o medo e a violência são utilizados para garantia da conjuntura de opressão da mulher-ser-potência? Em que medida a ideologia de gênero em questão impõe uma ética, uma estética e uma moral funcional para a manutenção desse sistema social opressor da mulher-ser-potência? Em que medida é doloroso para as mulheres serem subversivas em um mundo onde os significados e instituições estão estruturadas em cadeia para não serem modificadas em favor de uma lógica distinta à patriarcal? Como esses obstáculos interferem no livre deslocamento da mulher e, logo, no turismo?

O objeto de reflexão deste artigo, assim, impõe que compreendamos, como propusera Bourdieu (1996), os esquemas inconscientes da percepção e apreciação, as estruturas históricas da dominação masculina; que compreendamos o conjunto de fatores que condicionam as relações sociais de deslocamento das mulheres no presente. Nesse sentido, deve-se atentar para o fato de que os obstáculos que dificultam, ou mesmo inviabilizam a determinados espaços o caráter de público, ou seja, que impedem um uso e um deslocamento democrático e igualitário não são apenas de ordem físico/material (muros, cercas, alambrados etc.), mas que esses obstáculos ao livre deslocamento também são de ordem política (Lefebvre, 2011) e simbólica (Serpa, 2011). Logo, são elementos fundamentais para o entendimento do deslocamento da mulher: a representação, o medo, o corpo, a comunicação, a ação política, a insegurança, entre outros.

Ao abordar as categorias mulher e deslocamento, de pronto surgem os conflitos derivados dessa relação; conflitos esses que derivam da incompatibilidade da representação da mulher com o deslocamento livre e despreocupado - inibindo o caráter democrático do deslocamento. Assim, se o espaço é social, ele contém, antes de tudo, as representações das relações de poder, econômicas e de gênero que enquadram, também, as relações de deslocamento. Deste modo, pode-se dizer que historicamente o deslocamento é hierarquizado não apenas economicamente, mas seguindo outros parâmetros sociais, entre eles, o de gênero.

Para reforçar a argumentação aqui desenvolvida, traz-se Simone de Beauvoir, que refletindo sobre as condições do deslocamento da mulher no século XX, aclara empiricamente nossas indagações ao relatar que:

Da moça exigem que fique em casa, fiscalizam-lhe as saídas: não a encorajam em absoluto a escolher seus divertimentos, seus prazeres. É raro ver mulheres organizarem sozinhas uma longa viagem, a pé ou de bicicleta, ou dedicar-se a um jogo como o de bilhar, de bolas etc. Além de uma falta de iniciativa que provém de sua educação, os costumes tornam-lhe a independência difícil. Se passeiam pelas ruas, olham-nas, abordam-nas. (Beauvoir, 1980, p.71-72)

Ainda atualmente, quando se pensa no deslocamento turístico da mulher, tem-se a inércia da histórica objetificação que a impendia, e segue impedindo, ainda que de forma mais velada, de realizar determinadas atividades em diversas escalas. Alerta-se que esse empecilho não era, nem segue sendo imposto apenas na escala da casa, da rua, do bairro e da cidade, mas também na escala do deslocamento turístico, as viagens objeto de estudo desse artigo.

Tendo em vista os obstáculos simbólicos e políticos historicamente impostos às mulheres, indaga-se: como o deslocamento das mulheres é dificultado pelas representações patriarcais? Como, historicamente, esse 
processo atinge os deslocamentos turísticos? Como, hoje, esse processo interfere no desenvolvimento do segmento de viagens solo[2] para mulheres? Assim sendo, tem-se como questão problema: em que medida as representações patriarcais interferem no livre deslocamento turístico das mulheres que viajam sozinhas?

Fica evidente, portanto, que nosso interesse recai sobre as mulheres que viajam sozinhas, ou seja, tomaremos as viagens na modalidade solo como objeto empírico de análise para refletir a condição dos deslocamentos femininos no mundo contemporâneo. Para tanto, partimos da análise de blogs de viagens, mais especificamente de suas postagens de "dicas para mulheres que viajam sozinhas", buscando, hermeneuticamente, identificar como essas dicas poderiam esclarecer e exemplificar empiricamente os artifícios utilizados pelas mulheres na busca de um deslocamento/viagem turística menos permeado pelo medo do Outro e pela incerteza; esclarecer as táticas e estratégias utilizadas pelas mulheres ao viajarem sozinhas. Assim, espera-se demonstrar empiricamente que o deslocamento é determinado também segundo o gênero. Dessa forma, espera-se esclarecer que o gênero é uma categoria funcional aos estudos dos deslocamentos turísticos contemporâneos.

Cabe ainda destacar que se partiu das seguintes hipóteses empírica e teórica respectivamente: o conteúdo dos blogs serve como indicativo das opressões vinculadas às representações patriarcais que cerceiam a mulherser-potência e, consecutivamente seu deslocamento livre, despreocupado e democrático. Assim sendo, podese dizer que historicamente o deslocamento é hierarquizado não apenas economicamente, mas seguindo outros parâmetros sociais, entre eles, o de gênero.

\section{Metodologia}

No que concerne ao percurso metodológico deste estudo, utilizou-se, preponderantemente, dos resultados de uma revisão bibliográfica, pela qual se buscou compreender como a representação histórica da mulher tonou-se incompatível com o deslocamento livre. Para esse primeiro momento, foi conduzida uma coleta de artigos em plataformas confiáveis de indexação e diretamente no site de revistas eletrônicas nacionais e internacionais.

Após a seleção sistemática dos artigos e procurando um conteúdo empírico para posicionar a problemática aqui desenvolvida, buscou-se elencar publicações de blogs[3] que indicassem "dicas de viagem para mulheres sozinhas". Isso, pois acreditamos que a busca por dica (breve conselho/informação privilegiada) demonstra uma comunicação estratégica das mulheres para tentar reduzir as violências presentes no ato de se deslocar. Assim, acreditamos que essas dicas expressam a condensação de experiências individuais/coletivas e por expressar essa experiência, serve-nos como estruturas de redução fenomenológica intersubjetiva; serve-nos como material analítico capaz de aclarar um pouco mais essa relação conflituosa entre a representação patriarcal da mulher e o seu deslocamento.

Por tanto, selecionaram-se, através de uma amostragem aleatória na plataforma de busca Google, publicações de blogs distintos. Não se partiu, porém, de um ponto de saturação definido a priori, pois defendemos que a quantidade de dados a ser analisado não pode ser estabelecida em números. O que precisa prevalecer, segundo Minayo (2017, p. 10), é “[...] a certeza do pesquisador de que, mesmo provisoriamente, encontrou a lógica interna do seu objeto de estudo - que também é sujeito - em todas as suas conexões e interconexões." Não trabalhamos, portanto, com a noção de saturação, mas com o propósito de dar corpo a nossa investigação e torná-la defensável como afirmara Mason (2010). Por isso, preocupama-nos menos com as generalizações e mais com o aprofundamento dialético no processo de compreensão dos deslocamentos de mulheres no mundo contemporâneo. Ao final, totalizaram-se cinco publicações. Essas foram analisadas através de uma abordagem comparativa que buscou continuidades e descontinuidades no conteúdo dos textos. 
Numa perspectiva teórico-metodológica, traçou-se a categoria corpo como uma categoria analítica funcional ao entendimento do conteúdo discursivo presente nos blogs - será através dessa categoria que iremos analisar o dito conteúdo.

\section{CORPO E COMUNICAÇÃO: CATEgORIAS FUNDAMENTAIS AO ENTENDIMENTO DO DESLOCAMENTO DAS MULHERES}

Neste momento do texto, aproximando-nos ainda mais da problemática proposta neste ensaio, iremos tramar as categorias corpo e comunicação objetivando iluminar a discussão transversal do deslocamento da mulher através das dicas/estruturas de redução fenomenológicas dos já citados blogs.

Antes, porém, de adentrarmos na discussão central deste tópico, é necessário esboçar algumas palavras sobre as categorias corpo e comunicação, respectivamente.

O corpo, em sua concepção mais antiga, é tratado como instrumento da alma, servindo como uma prisão ou túmulo da mesma (Abbagnano, 2003). O corpo, nessa noção, seria apenas um instrumento natural da alma que, por sua vez, domina-o e o utiliza de várias formas. Nesse sentido e dentro de um tratamento essencialista, narrava-se a alma como tendo uma essência imutável - argumento funcional às relações de opressão de gênero. A alma da mulher, dentro desse tratamento essencialista, teria uma natureza subordinada aos homens. Subordinação essa que instrumentalizaria em seus corpos muitos territórios que, "naturalmente", cerceariam a liberdade no existir. Liberdade, cabe destacar, que vai ser historicamente cerceada através das armaduras de ideias contaminadas pelo patriarcado (Saffioti, 2004), como a ideia de beleza, ética, pudor, sexualidade etc. (Foucault, 1985).

É necessário aclarar também que essa abordagem do corpo enquanto instrumento da alma, coloca as problemáticas vinculadas ao corpo derivando de um movimento de dentro para fora, da essência para a aparência, porém acredita-se aqui que existe um movimento simultâneo, esse, invertido, de fora para dentro. As representações, as instituições e os valores socialmente construídos dentro do patriarcado - externos à alma -, criam uma armadura ideológica que oprime a mulher enquanto ser-potência.

É curioso pensar, nesse sentido, que a ideia do corpo ideal da mulher pode vir a assumir, em diferentes épocas e lugares, significações diversas fruto de determinações vinculadas aos aparelhos ideológicos (sistemas comunicativos, educacionais, policiais e políticos). Diante da conjuntura histórica de fortes imposições de massificação midiática, de novos dispositivos de controle imagético e social, não seria estranho conjecturar que o corpo pudesse vir a tomar outro lugar na escala de valores de nosso tempo, como propusera Pinheiro e Carvalho (2017). O corpo, assim, se fez uma categoria social inegável na discussão ora proposta. Isso, pois a exposição do corpo ao olhar de um outro anônimo nunca foi tão vivenciada e, simultaneamente, vigiada (Pinheiro \& Carvalho, 2017). Nos perfis de redes de relacionamento virtuais, nos registros em fotografias digitais postadas à nossa revelia na internet, nas câmeras de controle de segurança, nos cadastros de instituições das quais o sujeito participa, a imagem do corpo nunca foi passível de tamanha circulação, manipulação e avaliação por um Outro desconhecido.

Onde se quer chegar com essa discussão? Se quer defender que o corpo, hoje, é um ambiente permeado pela incerteza, pelo julgamento e pelas regulações do medo do Outro. Regula-se, hoje muito mais que antes, os Gestus e as palavras (Brecht, 1996), além dos objetos que adornam o corpo (Barthes, 1993, 2012; Baudrillard, 1995). Isso, pois, nesse cenário, não temos controle da visão do Outro sobre meu corpo. Reside nessa relação, assim, um campo cego da imagem que é feita de 'nós'. Isso torna o corpo um objeto do mais intenso investimento das preocupações contemporâneas. Existiria, nesse contexto, uma desigualdade de gênero nessa lógica? Dentro do histórico sistema de representação que constrói muito mais territórios no corpo da mulher do que em qualquer outro, as mulheres têm de se preocupar mais com o Outro? Essas preocupações poderiam ser tratadas como medos? O corpo da mulher estaria muito mais inscrito pelo medo do que outros? No ato de deslocar-se, o corpo ou a forma de se corporificar é marcada pelo medo do Outro? Como o corpo vem sendo 
utilizado para a tentativa de garantir um deslocamento menos cerceado? O deslocamento para o homem e para a mulher é cerceado na mesma proporção?

Deste modo, hoje, cuida-se do corpo e da forma como esse está adornado na busca de uma comunicação. Descobriu-se, em escala nunca antes vista, que o corpo comunica. Nessa paisagem discursiva, as formas como as mulheres utilizam dos seus corpos para comunicar, emergem como esquiva das operações, abusos e violências e/ou como movimento subversivo de busca pela liberdade desse corpo oprimido historicamente pelo patriarcado.

O sistema social do patriarcado consolidou, através das suas tramas de valores, instituições e representações, um estado de medo para as mulheres. Esse estado de medo talvez explique o porquê da corporificação da mulher ser constituída de mecanismos que restringem seu contato com o Outro; o porquê do espaço, para a mulher, ter se tornado historicamente um território de medo e insegurança. Deve-se aclarar, porém, que embora o medo seja uma das emoções consideradas naturais ao humano, é tomado nessa reflexão como uma emoção que é, como propõe Solomon (1995), constituída socialmente. Nesse sentido, cabe-se destacar que esses mecanismos de defesa não derivam somente pelo exercício e pela condição de violência cotidiana, mas por um estado de violência - evidente ou dissimulado - incorporado à cultura através das representações.

\section{Resultados e Discussões}

Neste momento do texto visando uma abordagem mais detalhada do conteúdo discursivo presente nas dicas retiradas dos blogs descritos na metodologia, trazemos tópicos que guiarão a discussão aclarando as dificuldades, estratégias de defesa e esquiva das opressões e violências inerentes ao ato de se deslocar da mulher.

\subsection{O corpo e seus adornos}

O corpo, conforme aclarado anteriormente, fala sem palavras. Ele comunica de forma distinta segundo a quantidade e a qualidade dos adornos que o cobrem. Assim, os objetos/adornos são elementos essenciais na análise da intenção de comunicação do corpo. Os objetos constituem um dos dados primários do contato do indivíduo com o mundo. $\mathrm{O}$ que devemos notar, porém, é que a própria existência do objeto é mensagem de um indivíduo a outro (Moles, 1981). O objeto é, portanto, comunicação; é portador de forma e mensagem, além da materialidade (Baudrillard, 1995). O corpo não é um objeto exatamente - ainda que possa tomar essa qualidade em alguns momentos -, mas está adornado por um sistema de objetos que, arranjados de forma intencional, ou não, comunica algo.

Arranjar os objetos no corpo de formas a buscar a esquiva das violências existentes no ato de deslocar, tem sido algo recorrente nas mulheres, como pode ser observado no fragmento abaixo:

B2: Usar uma aliança 'fake' [4] pode ajudar a te proteger quando estiver sozinha em um país estrangeiro. Isso porque, se houver algum mau elemento observando você, vai pensar que, mesmo estando sozinha em determinado lugar ou situação, o seu marido/companheiro/namorado deve estar por perto ou a caminho. A possível presença de um homem a qualquer momento faz com que você deixe de ser um alvo 'frágil e indefeso'. Pode parecer bobagem, mas ajuda sim. [Grifos nossos]

B5: Por sorte estava com alguns amigos homens e logo segurei no braço de um deles. Conheço mulheres que colocam um anel como se fosse aliança para evitar qualquer tipo de assédio. [Grifo nosso]

Com isso, alguns questionamentos são necessários para o entendimento dessa problemática, são eles: em que medida as mulheres precisam da companhia masculina ou da utilização de objetos que remetem a essa companhia para se sentirem seguras? Por que a figura da mulher não impõe, sem a companhia de um homem, o respeito necessário para um livre deslocamento? Pensemos: nas mulheres, o uso da aliança toma um caráter protetivo, freando o contato com o outro, a fim de garantir um deslocamento menos permeado pela violência causada pelo contato com esse outro potencialmente agressivo e preponderantemente masculino. 
O corpo feminino e seus adornos/objetos não são suficientes para evitar as agressões comuns ao deslocamento feminino. Nesse sentido "a possível presença de um homem a qualquer momento faz com que você deixe de ser um alvo 'frágil e indefeso'”. As mulheres, a fim de garantir um deslocamento com o mínimo risco de agressão, utilizam de elementos que comuniquem uma possível companhia masculina. O que nos direciona para uma discussão ética indispensável. Para isso gastaremos mais algumas linhas desse tópico para refletir sobre o reconhecimento da mulher como sujeito merecedor de respeito. Como mencionado no início desse tópico, o corpo não é um objeto exatamente, mas pode tomar essa qualidade em alguns momentos, porém, tomar caráter de objeto não é um movimento natural do corpo, mas produto de uma intenção de dominação. Pensemos: quando uma mulher utiliza das estratégias presentes nas dicas supramencionadas, a mesma manipula a forma como será reconhecida pelo potencial agressor - se antecipa a uma resposta agressiva provável do Outro. Se anteriormente a mesma tinha para ele o caráter de objeto, este que pode submeter-se as suas vontades, agora segue tendo igualmente o caráter de objeto, mas um objeto pertencente à um terceiro. Logo, a mulher não tem sua integridade física preservada em nome do respeito da qual é merecedora, mas da relação ética entre homens.

\subsection{Gestus: mulheres enquanto atrizes cotidianas}

Do latim, Gestus, é, como a palavra mesmo alude, aquilo que chamamos frequentemente de gesto no português. Ou seja, uma determinada postura corporal que expressa uma ideia ou sentimento, tornando-os visíveis aos outros. É a expressão física de certas relações sociais, do modo como os humanos se apresentam diante de outros humanos em sociedade. A noção de Gestus, portanto, refere-se ao caráter expressivo das atitudes humanas, tornando visíveis conteúdos que não se expressam por si mesmos. Por isso a noção de Gestus, inicialmente, define-se como apresentação, como "mostragem" (Brecht, 1996).

Para Brecht, é a partir das relações sociais que se deve distinguir o Gestus da simples gestualidade. Em suas palavras, "Nem todos os gestos são sociais. A atitude de espantar uma mosca não é um gesto social [...] O gesto de trabalhar é definitivamente social, porque toda atividade humana dirigida para a dominação da natureza é um empreendimento social." (Brecht, 1996, p.104). Discorrendo sobre o papel do ator, Brecht diz que a expressão/comunicação do corpo é determinada por um Gestus social. "Por Gestus social entendese a expressão mímica e gestual das relações sociais que prevalecem entre os homens de uma determinada época." (Brecht, 1996, p.281).

Deste modo, pode-se inferir que Gestus se refere ao sistema significativo de posturas e movimentos do corpo geográfica e historicamente situados - variando no tempo e no espaço. Esse sistema de significados se efetiva em gestos e atitudes que são utilizadas e modificadas pelos seres de acordo com diferentes situações socioespaciais e intenções. As mulheres, no ato de se deslocar, por exemplo, têm planejado seus Gestus a fim de esquivar das violências comuns ao deslocamento feminino. Para tanto, aparentando atrizes em cena, designam, estrategicamente, suas atitudes, posturas, expressões faciais, palavras, entonações, etc.

Os enxertos abaixo servem para elucidar nossa colocação:

B1: Embora cada vez mais gente - homens e mulheres - caiam na estrada desacompanhados, viajar solo ainda não é uma modalidade tão comum quanto com os amigos, companheiros ou familiares. Por isso, se você não der margem para outros verem que está sozinha, as pessoas vão supor que você viaja com alguém. Não deixe a porta do quarto aberta quando estiver lá dentro, e abra apenas uma parte se alguém bater.

Pergunte se há recados para você na portaria do hotel/pousada/hostel, assim dá a ideia de que está em contato com outra pessoa na cidade. Faça amizades ou apenas converse com estranhos quando estiver na área comum da sua hospedagem, passeio ou ponto turístico. E, se estiver caminhando pela rua ou à bordo de um transporte e não se sentir segura, pegue o telefone e faça uma ligação imaginária. Você dará a ilusão de que há alguém indo ao seu encontro ou esperando por você. [Grifos nosso]

B1: Virar uma esquina e não saber mais onde estamos é uma situação $100 \%$ comum em viagens. Mas, se você for mulher e estiver sozinha ao se perder, é bom ter um cuidado extra. Ficar parada no meio da rua olhando para todo lado com 
cara de boba é a mesma coisa que pintar um alvo em vermelho e preto no seu peito. Tirar o celular da bolsa para checar o Google Maps ou mesmo o velho e bom mapa de papel então, nem se fala.

Logo alguém virá oferecer ajuda, ou mesmo para levar você, e não há como saber se é uma pessoa bem intencionada ou não. Se estiver nesta situação, entre em qualquer estabelecimento comercial por perto para tentar se localizar ou mesmo pedir informações. Se não houver nenhuma lojinha nas proximidades, sente na escadaria de uma casa, fique em frente a um prédio com porteiro ou pare em algum canto discreto para tentar descobrir onde está. [Grifos nosso]

B4: Demonstre confiança: cuidado para não parecer que está perdida, ou que está com dúvida para onde ir. Aja com atitude e demonstre confiança, mesmo se alguma coisa fugir do seu controle. Essa "imagem" ajuda a manter os suspeitos longe. [Grifos nosso]

B5: Seja (ou aparente ser) confiante: Confesso que sou meio bicho do mato e uso esta regrinha não só quando estou viajando sozinha, mas em várias situações no dia a dia. Ande como se tivesse sempre um objetivo à cumprir, como se estivesse sempre indo a algum lugar, com hora marcada. Exale confiança e as pessoas vão te respeitar [...] Outra dica boa é usar a tática Michael Jordan e ter um fone de ouvido na bolsa. Assim, mesmo que não esteja ouvindo nada, ele vai ser bastante útil quando você não quiser responder àquela piadinha boba ou bater papo com um desconhecido enquanto espera numa fila. Se estiver ouvindo música, não deixe o volume muito alto para ouvir o que acontece ao seu redor. [Grifos nosso]

O medo é inscrito no corpo. O corpo, por sua vez, vai aparecer como campo de luta, resistência, estratégia e vai começar a se comunicar de modo que reduza o medo e a possibilidade, latente, de violência. Nesse sentido, indaga-se: como pensar na mulher-ser-potência dentro de uma conjuntura de cerceamento da liberdade?

Além dos cuidados com a postura, gestos e atitudes, outro cuidado também é comum no deslocamento de mulheres, a saber, o cuidado com a palavra. Vide fragmento abaixo:

B2: Não tenha medo de dizer não, não só para bebida, mas para qualquer tipo de situação. Em situações suspeitas, não revele que você está sozinha e tente sempre usar um "nós” na conversa, para dar ideia de que está acompanhada. [Grifos nosso]

Para Brecht (1996), as relações sociais marcam as características das personagens. Fica evidente, aqui, que as mulheres, no ato de se deslocar (em qualquer escala), acabam tendo que assumir uma atitude de atrizes cotidianas, construindo coletivamente personagens a fim de esquivar das violências inerentes ao seu deslocamento. A relação social desequilibrada e opressora promovida pelo sistema social patriarcal impõe que as mulheres construam personagens e que marquem nessas personagens suas características. Trata-se de um personagem criado e marcado pelo medo. $O$ pior dos fatos é que não se trata, aqui, de personagens de uma peça de teatro que são criadas com intenções artísticas, mas de personagens cotidianas construídas com a intenção de esquivar das opressões e das violências. Pode-se inferir, portanto, que as relações sociais de gênero engendradas pelo opressor sistema social patriarcal, têm motivado o uso de um sistema, marcado pelo medo, de signos/Gestus que serve como estratégia no deslocamento das mulheres.

Nesse sentido, concorda-se com Brecht, quando esse afirma que o entendimento do Gestus social e das formas como esse conjunto de signos comunicativos são utilizados, permite-nos entender a situação social. Isso, pois aqui permitiu lançar luz sobre aspectos das relações de opressão de gênero no deslocamento.

\subsection{Todo cuidado é pouco}

Neste tópico fica evidente na análise dos blogs que as restrições ao ato de se deslocar da mulher não se limitam às variáveis espaciais, mas também às temporais. Observemos os fragmentos textuais:

B1: Mesmo que você se sinta 100\% segura e esteja em lugares super turísticos, com policiamento reforçado. É fácil se perder em meio às luzes de Paris e sair sem rumo pela beira do Sena, se embriagando de tanta beleza. Mas, como já dissemos, uma mulher viajando sozinha é um alvo, pois, além de hipoteticamente 'frágil e indefesa', costuma estar distraída pelo que vê ao redor e carregar coisas de valor na bolsa, como câmeras fotográficas, smartphones e dinheiro da viagem.

Você nunca sabe se alguém não vai reparar que está sozinha visitando a Torre Eiffel e te seguir depois. Sempre pode existir uma esquina escura ou uma rua deserta no meio do seu caminho.

Saia à noite sim, todas as noites se quiser, mas não se arrisque sem necessidade. Se desloque de transporte público até as $22 \mathrm{~h}$, ou táxi se for mais tarde. [Grifos nossos] 
B5: Alguns países são mais amigáveis que outros: Se você nunca viajou sozinha, comece por locais onde sabe que as mulheres estarão mais seguras. [Grifos nossos]

As mulheres, no ato de pensar o destino e programar uma viagem, levam em consideração aspectos que ultrapassam o banal, por isso "[...] uma mulher viajando sozinha é um alvo [...]"; "[...]é bom ter em mente que pode se tornar vítima de roubos e abusos [...]”. Logo, ao mínimo descuido, tornam-se vulneráveis. A partir do momento que dicas como "preocupe-se com o horário", "desloque-se de forma segura" e "procure lugares amigáveis as mulheres" tornam-se corriqueiras, vemos esse deslocamento desestimulado, percebendo, como já apontado neste artigo, que o deslocamento não possui caráter democrático para as mulheres, isto ocorre porque o acesso ao espaço público, este compreendido por Serpa (2006, p.9) como "espaços que, em tese, seriam - o deveriam ser - acessíveis a todos", não lhes são garantidos.

Além das restrições já mencionadas, nota-se a nítida tentativa de alertar às mulheres das violências presentes no deslocamento solo, incentivando-as a buscar companhias a fim de evitar estas mesmas violências, como podemos observar nos seguintes fragmentos:

B1: Além de ser mais seguro para uma mulher que viaja sozinha, fazer tours com várias pessoas pode ser muito divertido e render boas amizades. É claro que um tour privado tem inúmeras vantagens, como poder controlar o tempo em cada lugar e ter as explicações só para si, mas também deixa você a mercê de pelo menos duas pessoas, provavelmente homens (motorista e guia).

Sem falar que, no tempo livre que você ganha em cada parada, poderá ser abordada por qualquer um. Nos passeios em grupo, você sempre terá alguém ao seu lado para apelar no caso de sentir algum tipo de perigo.

B2: Antes de viajar tente fazer amizade com alguém que more no local para o qual está indo através das redes sociais ou indicações dos seus próprios amigos. Isso será muito útil para esclarecer dúvidas quanto aos hábitos e costumes locais, como também para arranjar companhia para sair à noite ou mesmo conhecer algum local, caso esteja insegura em fazer absolutamente tudo sozinha.

B3: Para não se sentir sozinha, hospede-se em um hostel: Viajar sozinha não necessariamente é sinônimo de passar toda a viagem sozinha. A experiência em hostels geralmente permitem que você conheça pessoas de diferentes locais e culturas. Muitas vezes você pode encontrar pessoas que também estão viajando sozinhas, o que é uma ótima oportunidade para fazer amigos e obter companhias para passeios.

O sentimento coletivo de medo, expressa-se de maneira máxima quando se percebe a intenção das mulheres de portar objetos de defesa pessoal.

B1: Essa não é nenhuma novidade para mulheres que precisam enfrentar o dia a dia das ruas brasileiras, não é mesmo meninas? Pois, ao viajar sozinha para algum país estrangeiro, mantenha esse hábito e tenha algo na bolsa que possa te ajudar a enfrentar um hipotético ladrão ou abusador.

Escolha suas 'armas': há sprays do tipo pimenta, que fazem os olhos arder; equipamentos de choques elétricos, que paralisam o oponente; ou mesmo chaveiros pontudos de auto-defesa, [...]. E deixe sua bolsa sempre por perto, mesmo que vá mergulhar no mar, ou eles de nada servirão!

Ou seja, quando o arranjar dos objetos/adornos no corpo e sua intenção de comunicação se fazem insuficientes, recorre-se, em ato de desespero e medo, ao porte de objetos/“armas”.

\section{CONSIDERAÇÕES FINAIS}

As reflexões desenvolvidas nesse estudo permitem inferir que o deslocamento da mulher é dificultado em múltiplas escalas, alcançando inclusive o deslocamento turístico. Nesse sentido, torna-se um objeto legítimo, necessário e urgente aos estudos do Turismo, o entendimento das armaduras simbólicas da dominação masculina e suas implicações no deslocamento turístico de mulheres no mundo contemporâneo. Estudos esses que deverão estar em relação de fronteira, principalmente, com a Sociologia, a Geografia Cultural e a Antropologia, pois só assim alcançaremos novas possibilidades de trabalhar o entendimento dos deslocamentos femininos numa concepção interdisciplinar. Por isso, acreditamos que deve se ponderar 
o estudo do simbólico e do gênero como um possível fator impulsor de um debate renovado nos estudos dos deslocamentos turísticos das mulheres no mundo contemporâneo. Deve-se ponderar tal estudo, pois aprimorar o entendimento das influências simbólicas da dominação masculina no deslocamento turísticos das mulheres é possibilitar, num mesmo movimento, o entendimento de como o simbólico vêm interferindo na ampliação do segmento turístico de viagens solo de mulheres.

Julgamos, portanto, como sendo urgente aos estudos do Turismo um melhor entendimento desse objeto, isso pois, como já mencionado anteriormente nesse artigo, é uma verdade que quase nenhum empenho foi dedicado pelos pesquisadores brasileiros ao estudo da mulher na condição de sujeito que se desloca turisticamente e, tampouco às condições de tais deslocamentos. É também verdade que os estudos de gênero, desde a década de 1990, alcançaram os estudos do Turismo e proliferaram investigações críticas voltadas, sobretudo, ao Turismo sexual (Ribeiro, 1997; Torres, Davem \& Costa, 1999; Ribeiro, 2001; Silva, 2007; Gomes, 2008; Blanchette \& Silva, 2010; Dias Filho, 2010; Vivas, 2011; França, 2018). Porém, nesses estudos, a mulher, objetificada pelo mercado, pelas narrativas e discursos de Turismo sexual, aparece na análise enquanto agente motivador de deslocamentos turísticos. É sob essa perspectiva da relação mulherTurismo que os estudos do Turismo mais se debruçaram no Brasil. Propomos, aqui, que ampliemos nossas possibilidades de análise. Ou seja, que continuemos a estudar tais processos de objetificação da mulher e, logo, a mulher na condição de "produto turístico" - uma vez que esses seguem sendo uma realidade -, mas que estudemos a mulher também enquanto turista. De tal modo, abriremos a possibilidade de proliferar, sob influência dos estudos de gênero, outra paisagem interpretativa da relação mulher-Turismo - a do sujeito que se desloca - e das condições em que se dá seu deslocamento no mundo contemporâneo.

Fica evidente, portanto, que ao propor as reflexões desenvolvidas nesse artigo, pretendemos estimular a construção de categorias de análises que possibilitem representar as barreiras simbólicas que envolvem o deslocamento das mulheres no mundo contemporâneo; que possibilitem que não nos percamos, enquanto estudiosos do fenômeno turístico, na realidade turvada entregue a nós pelo conjunto de ideologia do patriarcado. Espera-se, assim, estimular a construção de recursos intelectuais que fortaleçam a busca incessante pelo visível e invisível, pela forma e conteúdo, pelo concreto e abstrato, pelo imediato e mediato que interferem no fenômeno do deslocamento turístico da mulher e na forma como concebemos as determinações que envolvem esses deslocamentos. Faz-se necessário, para tanto, formular estratégias intelectuais e sociais de reconhecimento das tramas simbólicas provenientes de uma sociedade patriarcal.

Ao estudar o caso do deslocamento de mulheres na sociedade contemporânea, pode-se inferir que o caráter simbólico e ideológico que marca a representação da mulher dentro de uma sociedade patriarcal, é onde reside a maior parcela dos obstáculos à liberdade. Portanto, defendemos aqui que só através de uma metodologia que garanta representar os aspectos simbólicos que cerceiam o deslocamento livre da mulher, que conseguiremos compreender os elementos não visíveis da dominação masculina; os elementos não visíveis que impedem a manifestação livre da potência da mulher.

Entendendo que as dicas são a condensação da experiência coletiva, defende-se e recomenda-se tal ferramenta como técnica para o estudo desses aspectos simbólicos. Isso, pois as dicas são um gênero discursivo e, logo, comunicação, linguagem. Em sendo linguagem, são dotadas de ideologia e expressam as lutas sociais, os conflitos de gênero, de classe, de raça etc. Portanto, uma fonte de dados legítima e funcional aos estudos culturais e sociológicos do Turismo.

Cabe destacar, que as dicas, além de funcionais aos estudos do Turismo enquanto elemento metodológico, denunciam, enquanto elementos empíricos, uma atitude estratégica de resistência, ou melhor, de sobrevivência da mulher em seus deslocamentos turísticos. Isso ocorre quando tomamos as dicas enquanto estratégia utilizada como recurso de segurança pelas mulheres.

Sabendo que as mulheres compõem maioria demográfica e de todo cerceamento simbólico do seu deslocamento, recomenda-se o estudo dos impactos causados pelos obstáculos apontados neste trabalho na participação ativa das mulheres no Turismo, na condição de turista. Em que medida essas dificuldades 
atrapalham a ampliação do segmento de viagens solo para as mulheres? Em que medida a continuação dessa lógica desigual de deslocamento é negativa também para a economia do setor?

Cabe lembrar que o grupo de mulheres objeto de estudo desse trabalho não representa a maior parcela; não representa, assim, a totalidade de mulheres cujo deslocamento é dificultado por fatores simbólicos. O grupo em questão, posiciona-se dentro desta totalidade, porém, enquanto parcela privilegiada socioeconomicamente; uma vez que só o acesso a atividade turística é, por si, um privilégio de classe. Acreditamos, aqui, que certamente existam particularidades no ato de deslocar de acordo com as diversas representações das mulheres e suas distintas condições socioculturais e geográficas. Ora mais dificultadas, ora menos, mas sempre submetidas à lógica das opressões de gênero, fundadas no conjunto de ideologias do patriarcado.

Caberia, portanto, indagar, em que medida há distinção nas condições de deslocamento quanto à Etnia, Raça, Religião, Território de origem e Classe? Essa última é aqui tratada como de maior urgência, uma vez que, dentro de um modo de produção desigual, as representações de gênero, que dificultam o deslocamento, se somam aos fatores da economia-política, também de maneira desigual e contraditória. Como se dão as relações de deslocamento das parcelas menos privilegiadas (mulheres pobres, mulheres negras, mulheres suburbanas, mulheres idosas)?

\section{REFERÊNCIAS}

Abbagnano, N. (2003). Dicionário de Filosofia. São Paulo: Martins Fontes.

Aristóteles. (2012). Metafísica. São Paulo: Edipro.

Barthes, R. (2012). Elementos de semiologia. Editora Cultrix.

Barthes, R. (1993). Mitologias. 9.a ed. Rio de Janeiro: Bertrand Brasil.

Baudrillard, J. (1995). A sociedade de consumo. Rio de Janeiro: Elfos.

Beauvoir, S. (1980). O segundo sexo II. Rio de Janeiro: Nova Fronteira.

Blanchette, T. G., \& Silva, A. P. da. (2010). "A Mistura Clássica": miscingenãąão e o apelo do Rio de Janeiro como destino para o turismo sexual. Bagoas-Estudos gays: gêneros e sexualidades, 4(2), p. 221-244.

Brecht, B. (1996). Teatro completo. Anaya: Espanha.

Chauí, M. (1991). O que é ideologia. São Paulo: Brasiliense.

Demo, P. (1981). Metodologia Cientifica em Ciências Sociais. São Paulo: Editora Atlas.

Dias Filho, A. J. (2010). As mulatas que não estão no mapa. Cadernos Pagu , 7(6) p. 51-66.

Follador, K. J. (2009). A mulher na visão do patriarcado brasileiro: Uma herança ocidental. Revista Fato \& Versões, $1(2)$, p. 3-16.

Foucault, M. (1985). História da sexualidade 3: o cuidado de si. Rio de janeiro: Graal.

Franc\#a, G. da R. A. (2018). Gênero, raça e colonização: A brasilidade no olhar do discurso turístico no Brasil e na França. Tese de Doutorado, Sorbonne. Paris: França.

Gomes, M. S. (2008). Dimensões simbólicas do turismo sexual. Anais do Seminário Internacional Fazendo Gênero, v. 8.

Laesser C, Beritelli P \& Bieger T. (2009). Solo Travel: Explorative Insights from a Mature Market (Switzerland). Journal of Vacation Marketing, 15(3), p. 217-227.

Lefebvre, H. (2011). Direito à cidade. São Paulo: Centauro, 2011.

Mason, M. (2010). Sample size and saturation in Phd studies using qualitative interviews. Forum qualitative social research, 11(3), p. 1-19

Minayo, M. C. S. (2017). Amostragem e saturação em pesquisa qualitativa: consensos e controvérsias. Revista Pesquisa Qualitativa, 5(7), p. 1-12.

Moles, A. A. (1981). Teoria dos Objetos. Rio de Janeiro: Edições Tempo Brasileiro. 
Pinheiro, M \& Carvalho, G. (2017). Singularity and myth: the body as a subversive power. Revista Latinoamericana de Psicopatologia Fundamental, 20(4), p. 728-748.

Ribeiro, M. A. C. (2001). Prostituição Feminina e Turismo na cidade do Rio de Janeiro. In: Turismo e Cultura, a história e os atrativos regionais. Porto Alegre: Ed. Santo Ângelo, URIAUM/FAPERGS.

Ribeiro, M. A. (1997) Prostituição de rua e turismo em Copacabana: a Avenida Atlântica e a procura do prazer. Revista Território. 2(3), p. 87-104.

Saffioti, H. I. B. (2004). Gênero, Patriarcado, Violência. São Paulo: Editora Fundação Perseu Abramo.

Serpa, A. (2011). O espaço público na cidade contemporânea. São Paulo: Contexto.

Silva, T. A. (2007). Turismo sexual, prostituição e gênero: uma discussão teórica, Disponível em: http://www.uesc.b $\mathrm{r} /$ seminariomulher/anais/PDF/Mesas/TATIANA\%20AMARAL\%20SILVA.pdf. Acesso em: 29 de março de 2019.

Solomon, R. (1995). Emotions in Sian Thought. Albany: State University of New York Press.

Torres, G. de V.; Davim, R. M. B. \& Costa, T. A. da. (1999). Prostitution: reasons and future perspectives in a group of young girls. Revista latino-americana de enfermagem, 7(3), p. 9-15.

Vivas, L. M. B. (2011). Interseções entre gênero, raça, turismo e exploração sexual no Caribe: o caso de antígua. Revista Brasileira do Caribe, 12(23), p. 191-220.

\section{Notas}

[1] É uma verdade que os estudos de gênero, desde de a década de 1990, alcançaram os estudos do Turismo e proliferaram investigações críticas voltadas, soblretudo, ao Turismo sexual, suas narrativas e discursos que, em conjunto, construíram um objetificação do mulher - a mulher aparece nessa linha de abordagem, portanto, enquanto "produto turístico" (Ribeiro, 1997; Torres, Davem \& Costa, 1999; Ribeiro, 2001; Silva, 2007; Gomes, 2008; Blanchette \& Silva, 2010; Dias Filho, 2010; Vivas, 2011; França, 2018). É sob essa perspectiva da relação mulher-Turismo que os estudos do Turismo mais se debruçaram no Brasil. Porém, é também verdade que quase nenhum empenho foi dedicado pelos pesquisadores brasileiros ao estudo da mulher na condição de sujeito que se desloca turisticamente e, tampouco às condições de tais deslocamentos - essa é a perspectiva que pretendemos fortalecer com esse escrito.

[2] Entendendo-se como Solo Traveller o turista que viaja sem acompanhante e que pode - ou não - ser completamente independente, optando pela flexibilidade e liberdade que um pacote mais estruturado não oferece, porém com uma viagem minimamente organizada, podendo interpretar diferentes papéis, desde o turista de massas ao turista completamente independente (Laesser et al., 2009).

[3] Todos os blogs utilizados no texto foram identificados pela inicial e por numeração definida na sistematização das informações tabuladas na pesquisa. A saber:

B1, Disponível em: <http://www.escolhaviajar.com/dicas-para-mulher-viajar-sozinha/ > Acesso em: 19 de fevereiro de 2019 (Data da publicação: 08/02/2018; Acessos: não disponível; Quantidade de seguidores: 36.859 em junho de 2020).

B2, Disponível em: <https://instaviagem.com/blog/inspiracao/20-dicas-para-mulheres-viajarem-sozinhas-em seguranca/?utm_source=catraca\&utm_medium=20dicasmulher $>$ Acesso em: 19 de fevereiro de 2019 (Data da publicação: 17/11/2017; Acessos: 22.467; Quantidade de seguidores: $78.400 \mathrm{em}$ junho de 2020).

B3, Disponível em: <https://www.dicasdemulher.com.br/dicas-e-motivos-para-viajar-sozinha/> Acesso em: 19 de fevereiro de 2019 (data da publicação: 09/06/2017; Acessos: não disponível; quantidade de seguidores: 23.268 em junho de 2020$)$.

B4, Disponível em: <http://vidasemparedes.com.br/dicas-de-seguranca-mulheres-viajar-sozinhas/> Acesso em: 19 de fevereiro de 2019 (data da publicação: 04/12/2017 Acessos: 2205; quantidade de seguidores: 13.879 em junho de 2020). B5, Disponível em: <https://veja.abril.com.br/blog/modo-aviao/7-dicas-para-mulheres-que-viajam-sozinhas/> Acesso em: 19 de fevereiro de 2019 (Data da publicação: 07/02/2017; Acessos: não disponível; Quantidade de seguidores: 1.646.06 em junho de 2020).

[4] Falsa. 